\title{
Warfarin treatment quality and prognosis in patients with mechanical heart valve prosthesis
}

\author{
Bartosz Grzymala-Lubanski, ${ }^{1}$ Peter J Svensson, ${ }^{2}$ Henrik Renlund, ${ }^{3}$ Anders Jeppsson,,${ }^{4,5}$ \\ Anders Själander ${ }^{1}$
}

- Additional material is published online only. To view please visit the journal online (http://dx.doi.org/10.1136/10. 1136/heartjnl-2016-309585).

1 Department of Public Health and Clinical Medicine, Umeå University, Umeå, Sweden ${ }^{2}$ Department of Coagulation Disorders, University of Lund, Malmö, Sweden ${ }^{3}$ Uppsala Clinical Research Center, Uppsala University, Uppsala, Sweden

${ }^{4}$ Department of Cardiothoracic Surgery, Sahlgrenska University Hospital, Göteborg, Sweden

${ }^{5}$ Department of Molecular and Clinical Medicine, Institute of Medicine, Sahlgrenska Academy, University of Gothenburg, Göteborg, Sweden

\section{Correspondence to}

Dr Bartosz Grzymala-Lubanski, Department of Public Health and Clinical Medicine, Skogsstjarnevagen 61 80646 Gavle, Sweden; bartlubanski@gmail.com

Received 4 March 2016 Revised 26 July 2016 Accepted 27 July 2016 Published Online First 2 September 2016

\section{SLinked}

- http://dx.doi.org/10.1136/ heartjnl-2016-310369

\section{CrossMark}

\section{To cite: Grzymala-}

Lubanski B, Svensson PJ

Renlund $\mathrm{H}$, et al. Heart

2017:103:198-203.

\section{ABSTRACT}

Objectives To study the impact of time in therapeutic range (TTR) and international normalised ratio (INR) variability on the risk of thromboembolic events, major bleeding complications and death after mechanical heart valve (MHV) implantation. Additionally, the importance of different target INR levels was elucidated.

Methods A retrospective, non-randomised multicentre cohort study including all patients with mechanical heart valve (MVH) prosthesis registered in the Swedish National Quality Registry Auricula from 2006 to 2011. Data were merged with the Swedish National Patient Registry, SWEDEHEART and Cause of Death Registry.

Results In total 4687 ordination periods, corresponding to 18022 patient-years on warfarin, were included. High INR variability (above mean $\geq 0.40$ ) or lower TTR $(\leq 70 \%)$ was associated with a higher risk of bleeding (rate per 100 years 4.33 (95\% Cl 3.87 to 4.82 ) vs 2.08 (1.78 to 2.41$) ;$ HR 2.15 (1.75 to 2.61 ) and 5.13 (4.51 to 5.82 ) vs 2.30 (2.03 to 2.60); HR 2.43 (2.02 to 2.89$)$ ), respectively. High variability and low TTR combined was associated with an even higher risk of bleedings (rate per 100 years $4.12(95 \% \mathrm{Cl} 3.68$ to 4.51) vs 2.02 (1.71 to 2.30$) ;$ HR 2.16 (1.71 to 2.58 ) and 4.99 (4.38 to 5.52) vs 2.36 (2.06 to 2.60$) ; \mathrm{HR}$ 2.38 (2.05 to 2.85)) compared with the best group.

Higher treatment intensity (mean INR 2.8-3.2 vs 2.2-2.7) was associated with higher rate of bleedings (2.92 (2.39 to 3.47) vs 2.48 (2.21 to 2.77 ); HR 1.29 (1.06 to 1.58$)$ ), death (3.36 (2.79 to 4.02$)$ vs 1.89 (1.64 to 2.17$)$, HR 1.65 (1.31 to 2.06)) and complications in total (6.61 (5.74 to 7.46) vs 5.65 (5.20 to 6.06$) ;$ HR 1.24 (1.06 to 1.41)) after adjustment for MHV position, age and comorbidity.

Conclusions A high warfarin treatment quality improves outcome after MHV implantation, both measured with TTR and INR variability. No benefit was found with higher treatment intensity (mean INR 2.83.2 vs $2.2-2.7)$.

\section{INTRODUCTION}

Approximately five million prosthetic heart valves have been implanted over the last 50 years and annually over 300000 new prostheses are implanted. ${ }^{1}$ In Sweden, with 10 million inhabitants, more than 20000 patients live with a valve prosthesis and 2600 new heart valve procedures are performed every year. In $75 \%$ of the cases this is due to disease of the aortic valve, which usually needs to be replaced with a bioprosthesis or a mechanical prosthesis. The mitral valve can in approximately $70 \%$ of the cases be repaired instead of replaced. ${ }^{2}$ The majority of implanted valves in Sweden today are bioprostheses, whereas 35\% of mitral valve and $20 \%$ of aortic valve prostheses are mechanical. ${ }^{2}$

Mechanical heart valves (MHVs) demand lifelong anticoagulation with a vitamin $\mathrm{K}$ antagonist, most commonly warfarin, due to the high thrombogenicity of the prostheses. Current European and North American guidelines about anticoagulation in patients with MHV are mainly based on observational data and expert opinions. The guidelines are highly variable; there is, for example, no agreement whether antiplatelet therapy should be added to the anticoagulation or not. ${ }^{3-5}$ Furthermore, there is no consensus over the optimal level of anticoagulation treatment (target international normalised ratio, INR) in different patient populations, that is, the level providing protection against thromboembolism and at the same time not increasing the risk for bleeding.

The quality of the warfarin treatment has in several studies been shown to be of utmost importance in patients treated with warfarin due to atrial fibrillation (AF). ${ }^{6}$ In patients with $\mathrm{AF}$ with high time in therapeutic range (TTR) the risk for thromboembolic and bleeding complications is markedly lower than in patients with low TTR. ${ }^{6}$ In contrast, there are little data available about the importance of warfarin treatment quality in patients with MHV. The reports indicate that the quality also influences outcome in this patient population but the studies have so far included limited study populations and follow-up times. ${ }^{78}$

Besides TTR, warfarin treatment quality can be assessed by measuring INR variability. ${ }^{9}$ In a recent study in patients with AF, measuring INR variability in addition to TTR added information and increased the prognostic value compared with just TTR assessment. ${ }^{10}$ Also with INR variability, there are only limited data available in patients with MHV. ${ }^{11}$

No large contemporary study has investigated how the quality of warfarin treatment influences the risk for complications in patients with mechanical valve prostheses. Furthermore, no previous study has assessed the importance of warfarin quality with both TTR and INR variability in the same large cohort of patients with MHV. The aim of the present study was thus to evaluate the impact of TTR and INR variability, both individually and combined, on the risk for thromboembolic and bleeding complications in patients with MHV using data from Swedish national quality registries. 
In addition, we elucidated the risks and benefits of different INR levels in patients with aortic and mitral mechanical prostheses.

\section{MATERIAL AND METHODS}

\section{Data sources}

The present study cohort was created by merging data from four national Swedish patient quality registries using Swedish social security numbers which is a unique number for each inhabitant in Sweden: Auricula, the Swedish National Patient Registry, SWEDEHEART/Heart surgery and the Swedish Cause of Death Registry. After merging the registries, the data were de-identified.

Auricula is a web-based national quality register sponsored by funds from the Swedish Association of Local Authorities and Regions. Established in 2006, it has today more than 200 affiliated centres managing their daily dosing of oral anticoagulants, both warfarin and new oral non-vitamin $\mathrm{K}$ antagonists through the system. Auricula includes a decision support for dosing of warfarin. A suggested dose must always be either confirmed or changed by the medical doctor (MD) or specialised nurse performing the daily dosing. While using the system, quality parameters are automatically registered. The primary end points, major bleeding and thromboembolic events, are recorded prospectively. The system currently consists of over 120000 patients and more than seven million doses of warfarin corresponding to approximately $50 \%$ of all patients treated with oral anticoagulation in Sweden in 2015. The present study consists of patients included in Auricula from 2006 to 2011 which corresponds to approximately $20 \%$ of all patients with MHV prostheses in Sweden during this time period. ${ }^{12}$

SWEDEHEART/Swedish Heart Surgery Registry is a national quality register that contains data about all implanted heart valves in Sweden since 1992 with details such as valve type, size and position. ${ }^{13}$

The Swedish Patient Registry is the source of data on complications covering all diagnoses from the patients' records within hospitals throughout Sweden, both for inpatient (since 1987) and outpatient (since 2001) care. It does not cover primary care. The validity is high with missing information about the primary diagnosis at discharge in only $0.5-0.9 \%$ of the cases. ${ }^{14}$

The Cause of Death Registry contains data from 1961 onwards, and provides information about death date, and primary and contributing causes of death for all Swedish citizens.

\section{Study design}

A retrospective, non-randomised multicentre cohort study was performed. The study cohort consisted of 3831 patients who had 4687 ordination periods registered between January 2006 and December 2011, with a total of 18022 patient-years of warfarin treatment. An ordination period is a time period under which a patient has been treated with warfarin with the same treatment indication and INR target range. Patient characteristics are reported in table 1.

Mechanical tricuspid valves $(n=10)$ and patients lacking information on TTR $(n=134)$ were excluded. Every ordination period registered in Auricula has got an individual identification number. Patients could have one or more ordination periods during the study, mainly due to changes in target INR or concomitant treatment indications for warfarin. For treatments started before and continuing after the study period, the study's start and end dates were used. Patients with MHV both in the aortic and mitral positions were assigned to the mitral group,
Table 1 Baseline characteristics according to indication for warfarin

\begin{tabular}{|c|c|c|c|}
\hline & $\begin{array}{l}\text { All } \\
n=4687\end{array}$ & $\begin{array}{l}\text { Aortic valve } \\
\mathrm{n}=3656\end{array}$ & $\begin{array}{l}\text { Mitral } \\
\text { valve* } \\
n=1031\end{array}$ \\
\hline Mean age (SD) & $63.26(13.43)$ & 62.91 (12.94) & 64.51 (13.98) \\
\hline Female sex n (\%) & $1442(30.8)$ & $1022(28.0)$ & $420(40.7)$ \\
\hline Mean interpolated INR (SD) & $2.65(0.43)$ & $2.63(0.43)$ & $2.73(0.45)$ \\
\hline $\operatorname{TTR}(\mathrm{SD})$ & 72.5 (19.6) & $74.2(18.5)$ & $66.7(23.6)$ \\
\hline Target INR $2.5 \mathrm{n}(\%)$ & $3076(65.6)$ & $2581(70.8)$ & $495(48.1)$ \\
\hline Target INR 3.0 n (\%) & $400(8.5)$ & $158(4.3)$ & $242(23.5)$ \\
\hline
\end{tabular}

Treatment periods in patients with at least one diagnosis in the National Patient Register before warfarin start

\begin{tabular}{|c|c|c|c|}
\hline & $n=4299$ & $n=3332$ & $n=967$ \\
\hline Diabetes n (\%) & $468(10.9)$ & $348(10.4)$ & $120(12.4)$ \\
\hline Hypertension n (\%) & $1242(28.9)$ & $980(29.4)$ & $262(27.1)$ \\
\hline Previous stroke/TIA n (\%) & $511(11.9)$ & $377(11.3)$ & $134(13.9)$ \\
\hline Liver disease n (\%) & $26(0.6)$ & $18(0.5)$ & $8(0.8)$ \\
\hline Kidney disease n (\%) & $136(3.2)$ & $92(2.8)$ & $44(4.6)$ \\
\hline COPD n (\%) & $154(3.6)$ & $104(3.1)$ & $50(5.2)$ \\
\hline Atrial fibrillation $\mathrm{n}(\%)$ & $1483(34.5)$ & $936(28.1)$ & $547(56.6)$ \\
\hline Heart failure n (\%) & $1160(27.0)$ & 730 (21.9) & $430(44.5)$ \\
\hline $\begin{array}{l}\text { Previous major bleeding } n \\
(\%)\end{array}$ & $288(6.7)$ & $207(6.2)$ & $81(8.4)$ \\
\hline \multicolumn{4}{|c|}{$\begin{array}{l}\text { Mean age and gender are presented for all patients, concomitant diseases only for } \\
\text { those patients who had at least one diagnosis in the patient register before start of } \\
\text { warfarin. Presented as number and proportion of patients, n (\%). A patient could } \\
\text { have one or several indications for warfarin treatment. } \\
\text { *Includes patients with both aortic and mitral prostheses. } \\
\text { COPD, chronic obstrucitve pulmonary disease; INR, international normalised ratio; } \\
\text { TTR, time in therapeutic range. }\end{array}$} \\
\hline
\end{tabular}

due to the inherent higher risk of complications and higher target INR in this patient group. ${ }^{3-5}$

\section{Definitions/end points}

Types of complications registered were bleedings, thromboembolic events and death.

Major bleeding was defined as an event demanding hospital treatment and a discharge diagnosis with one of the international classification of diseases (ICD)-10 codes reflecting bleeding as listed in the online supplementary appendix. Bleeding events were divided into intracranial, gastrointestinal and other bleedings. Thromboembolic complications consist of venous (deep vein thrombosis, pulmonary embolism, venous stroke) or arterial events (stroke, TIA, acute myocardial infarction, peripheral arterial embolism). The ICD-10 codes constituting each complication are listed in the online supplementary appendix. A patient could have any and all types of complications during one ordination period but only one of each type, to prevent over-registering. All complications are presented as events per 100 patient-years.

\section{Quality of warfarin treatment}

TTR is a variation of Rosendaal et $a l ;^{15}$ it is calculated by looking at the piecewise linear curve made up by the interpolation of the INR measurements per ordination period (such that the difference between measurements does not exceed 90 days). The fraction of time that such a curve spends within the interval $2-3$ is the TTR. High TTR was defined as $\geq 70 \%$ according to 
the current guidelines from European Society of Cardiology. ${ }^{16} 17$ The variability refers to the SD of the curve, that is, a measure of spread about the mean of the curve. This is similar to Fihn et al, ${ }^{18} 19$ although they consider spread around a target value. For INR variability there is no established cut-off level, therefore the mean value of 0.40 was arbitrarily chosen. High or low TTR and INR variability was used to define four groups ranging from the best treatment quality (TTR $\geq 70 \%$ and INR variability $\leq 0.40$ ) to the worst (TTR $<70 \%$ and INR variability $>0.40$ ). Patients were also divided into four quartiles depending on their individual TTR: <62.18, 62.19-76.28, $76.29-86.41$ and $\geq 86.42 \%$ or INR variability: $\geq 0.5201$, $0.4001-0.5200,0.3001-0.4000$ and $\leq 0.3000$. All TTR and INR variability data are calculated per ordination period and not per patient.

\section{Warfarin intensity}

Patients with mitral or aortic valves were analysed separately regarding their actual mean INR which was determined by interpolation of the patient's INR values. These actual INR levels were divided into those between 2.2 and 2.7 and those between 2.8 and 3.3, which should correspond to an INR range of $2.0-3.0$ or $2.5-3.5$, respectively. In clinical practice, patients could be managed in the lower or higher range of their intended INR treatment ranges, thus the intended target INR groups and actual INR level groups may differ. The different actual INR levels were compared, both unadjusted and after adjustment for age (defined as age at the beginning of every ordination period), location of valve prosthesis, AF, heart failure, hypertension, diabetes and stroke.

\section{Statistics}

Incidence rates per 100 patient-years were calculated using OpenEpi, V.3.03 (http://www.openepi.com). A 95\% CI of person-time incidence rate with normal approximation was calculated for rates of complications. ${ }^{20}$ The different INR quality groups were compared regarding incidence rate of thromboembolism, bleeding and death per 100 treatment years. Incidence rates where the 95\% CIs did not overlap were considered to be statistically different from each other.

Data were analysed using SPSS Statistics (V.22; SPSS, IBM, New York, USA), and R V.3.0.0, R Foundation for Statistical Computing, Vienna, Austria, (http://www.R-project.org/) with survival analysis with Cox regression and t-test. The assumption of proportional hazards was tested and held for each factor using log minus log plots which confirmed Cox regression being an adequate analysis method. A sensitivity analysis (Fine and Gray) using death as a competing risk was conducted. Data distribution was normal (tested with one-sample KolmogorovSmirnov test). A p value $<0.05$ was considered statistically significant.

\section{RESULTS}

\section{General}

Of the total 4687 ordination periods, 3656 (78\%) concerned prosthesis in the aortic position, $842(18 \%)$ in mitral and 189 $(4 \%)$ in both positions. Thirty-one per cent of all patients were women, while women constituted over $40 \%$ of the patients with prosthesis in the mitral position. Patient characteristics are reported in table 1 .

\section{Complications}

Total rate of thrombotic events among all patients was 2.41 per 100 treatment years, of which 1.40 were arterial. There was no significant difference in rate of thrombotic events between different valve positions (table 2).

Total rate of major bleeding among all patients was 3.15 per 100 treatment years, of which 0.47 were intracranial. MHV prosthesis in mitral position was associated with significantly higher rate of bleeding complications (except for GI bleedings) and death but not for thromboembolism (table 2).

Total mortality among all patients was 2.42 per 100 treatment years with significantly higher rate in patients with a MHV prosthesis in the mitral compared with the aortic position (table 2).

\section{Warfarin treatment quality}

Time in therapeutic range

Mean TTR was $72.5 \%(\mathrm{SD}=19.6)$ and was clearly higher among patients with prosthesis only in the aortic position. Mean INR was $2.65(\mathrm{SD}=0.43)$, these data and comorbidity are presented in table 1 .

Lower TTR $(\leq 70 \%)$ was associated with significantly higher rate $(\mathrm{p}<0.001$ in all cases) of all and any type of complications when compared with TTR $>70 \%$ (table 3 ). Bleeding risk was higher in the group with lower TTR $(\mathrm{HR}=2.43$, 95\% CI 2.02 to $2.89, \mathrm{p}<0.001)$. After dividing patients into TTR quartiles the rate of complications in total was significantly higher in quartile 1- 3 when compared with quartile 4 with the highest TTR. Risk of thromboembolism, major bleeding and death was higher in the first and second quartiles as compared with the quartile with the highest TTR (table 4).

\section{INR variability}

Higher INR variability above mean $(\geq 0.40)$ was related to a higher rate of all and any type of complications $(p<0.001$ in all cases) compared with lower INR variability $(<0.40)$, (table 3 ). Bleeding risk was higher in the group with INR variability $\geq 0.40$ ( $\mathrm{HR}=2.15 ; 1.75$ to $2.61, \mathrm{p}<0.001)$.

When comparing quartile 4 with the lowest INR variability with the rest, quartiles 1 and 2 with the highest INR variability had significantly worse outcome for all complications except for thromboembolic events and death in quartile 2 (table 4).

\section{TTR and INR variability combined}

When both TTR and INR variability were divided into high or low according to the same principles as above, patients with both high TTR and low variability had the lowest risk of complications (table 5). High variability in a high TTR setting was

Table 2 Rate of complications per 100 treatment years with 95\% $\mathrm{Cl}$ in all patients and depending on MHV position

\begin{tabular}{llll}
\hline & $\begin{array}{l}\text { All patients } \\
\mathbf{n}=4687\end{array}$ & $\begin{array}{l}\text { Aortic valve } \\
\mathbf{n}=3656\end{array}$ & $\begin{array}{l}\text { Mitral valve } \\
\mathbf{n}=1031^{*}\end{array}$ \\
\hline Bleedings & $3.15(2.88$ to 3.44$)$ & $2.88(2.60$ to 3.19$)$ & $4.31(3.60$ to 5.11$)$ \\
CNS & $0.47(0.37$ to 0.59$)$ & $0.41(0.31$ to 0.53$)$ & $0.72(0.46$ to 1.08$)$ \\
GI & $1.05(0.90$ to 1.22$)$ & $0.96(0.80$ to 1.14$)$ & $1.43(1.05$ to 1.91$)$ \\
Other & $1.54(1.36$ to 1.74$)$ & $1.43(1.23$ to 1.65$)$ & $2.02(1.55$ to 2.58$)$ \\
Thromboses & $2.41(2.17$ to 2.66$)$ & $2.36(2.10$ to 2.64$)$ & $2.61(2.07$ to 3.25$)$ \\
Venous & $0.01(0.003$ to 0.3$)$ & $0.01(0.004$ to 0.4$)$ & 0 \\
Arterial & $1.40(1.22$ to 1.59$)$ & $1.34(1.15$ to 1.55$)$ & $1.65(1.24$ to 2.17$)$ \\
AMI & $0.95(0.81$ to 1.11$)$ & $0.96(0.80$ to 1.14$)$ & $0.90(0.60$ to 1.29$)$ \\
Death & $2.42(2.2$ to 2.65$)$ & $2.16(1.93$ to 2.41$)$ & $3.50(2.92$ to 4.17$)$ \\
\hline *Includes patients with both aortic and mitral prostheses. \\
AMl, acute myocardial infarction; CNS, central nervous system; Gl, gastro-intestinal; \\
MHV, mechanical heart valve.
\end{tabular}


Table 3 Rate of complications per 100 treatment years with $95 \%$ $\mathrm{Cl}$, according to MHV position, intended INR target, or warfarin treatment quality measured as TTR or INR variability, using TTR $70 \%$ or the mean INR variability of 0.40 as cut-off

\begin{tabular}{|c|c|c|c|}
\hline & Bleedings & Thromboses & Death \\
\hline \multicolumn{4}{|c|}{ Aortic valve prosthesis, $\mathrm{N}=3656$} \\
\hline $\begin{array}{l}\text { Actual INR } \\
2.2-2.7\end{array}$ & 2.74 (2.41 to 3.12$)$ & $2.42(2.10$ to 2.77$)$ & 1.79 (1.53 to 2.08$)$ \\
\hline $\begin{array}{l}\text { Actual INR } \\
2.8-3.3\end{array}$ & 3.02 (2.35 to 3.81$)$ & $2.28(1.71$ to 2.98$)$ & 2.97 (2.36 to 3.69$)$ \\
\hline \multicolumn{4}{|c|}{ Mitral valve prosthesis, $\mathrm{N}=1031$} \\
\hline $\begin{array}{l}\text { Actual INR } \\
2.2-2.7\end{array}$ & 4.73 (3.72 to 5.94$)$ & 2.95 (2.17 to 3.93$)$ & $2.48(1.80$ to 3 to 33$)$ \\
\hline $\begin{array}{l}\text { Actual INR } \\
2.8-3.3\end{array}$ & 3.97 (2.89 to 5.33$)$ & 2.63 (1.77 to 3.77$)$ & 4.17 (3.16 to 5.41$)$ \\
\hline \multicolumn{4}{|l|}{ Variability } \\
\hline$\leq 0.4000$ & 2.08 (1.78 to 2.41$)$ & 1.90 (1.61 to 2.22$)$ & 1.51 (1.26 to 1.79$)$ \\
\hline$\geq 0.4001$ & 4.33 (3.87 to 4.82 ) & 2.96 (2.59 to 3.38$)$ & 3.31 (2.93 to 3.74$)$ \\
\hline \multicolumn{4}{|l|}{ TTR } \\
\hline$\geq 70 \%$ & 2.30 (2.03 to 2.60$)$ & 2.13 (1.86 to 2.41$)$ & 1.68 (1.47 to 1.93$)$ \\
\hline$<70 \%$ & 5.13 (4.51 to 5.82 ) & 3.05 (2.58 to 3.59 ) & 4.00 (3.50 to 4.54$)$ \\
\hline
\end{tabular}

associated with higher risk for all complications compared with low variability. Patients with low TTR and low variability had higher risk for bleedings and death than the first group with high TTR and low variability, though not compared with those with high TTR and high variability. Finally, the group with low TTR and high variability had higher risk of bleeding (4.12 (3.68 to 4.51$)$ vs 2.02 (1.71 to 2.30$)$; HR 2.50 (1.99 to 3.15$)$ when compared with the best group) and death (4.28 (3.68 to 4.94) vs 1.34 (1.10 to 1.62 ); HR 3.34 (2.62 to 4.27) when compared with the best group) when compared with those with high TTR regardless of INR variability. They also had a higher risk of thromboses (2.91 (2.42 to 3.46$)$ vs 1.76 (1.48 to 2.08 ); HR 1.55 (1.21 to 1.99$)$ ) when compared with the best group, but did not differ in risk of any complication with those with same TTR but lower INR variability (table 5).

\section{Warfarin treatment intensity}

When divided into groups due to different prosthesis location, patients with aortic prosthesis and actual mean INR between 2.8 and 3.3 had a higher rate of death compared with patients with an actual mean INR between 2.2 and 2.7 (table 3). Other complication rates did not differ significantly between patients with different actual mean INR regardless of the MHV position (table 3).

Patients with an actual mean INR of 2.8 to 3.3 analysed as a whole group (irrespective of valve prosthesis location) had significantly higher rate of complications in total 6.61 (5.74 to 7.46) vs 5.65 (5.20 to 6.06 ); adjusted HR 1.24 (1.06 to 1.41 ), bleedings 2.92 (2.39 to 3.47 ) vs 2.48 (2.21 to 2.77$)$; adjusted HR 1.29 (1.06 to 1.58$)$ and death $3.36(2.79$ to 4.02$)$ vs 1.89 (1.64 to 2.17); adjusted HR 1.73 (1.38 to 2.16), compared with a lower actual mean INR. HRs both before and after adjustment for MHV position, age and comorbidity are presented in figure 1 .

Using death as a competing risk factor for the other complication events showed similar results as in the original Cox regression analyses.

\section{DISCUSSION}

In this large, national register study comprising 3831 patients with MHV with a total of 18022 treatment years on warfarin, a strong correlation between warfarin treatment quality measured by TTR and INR variability and serious complications was demonstrated. In order to reduce the risk of complications, every effort should be taken to keep the patient's TTR as high and INR variability as low as possible.

On the centre level, TTR is suggested to be kept above $70 \%$ for patients with $\mathrm{AF}^{18}{ }^{19}$ Using TTR $70 \%$ as cut-off in our cohort of patients with MHV, inferior TTR corresponded to both a doubled rate of bleedings and death and a 50\% higher rate of thromboembolic events. The current results support and extend the results from a previous study from our group where TTR influenced the risk of bleedings and death, but not thromboembolic events, in patients with $\mathrm{MHV}^{8}$ One way to increase TTR is using a computer-aided warfarin dosing system. $^{21} 22$ Other important factors for a high TTR are patient information and compliance, which in Sweden is achieved at least partly due to a good organisation with outpatient clinics based on specialised nurses.

Table 4 Multivariable Cox regression, risk of complications according to TTR and INR variability divided into quartiles

\begin{tabular}{|c|c|c|c|c|}
\hline Quartiles & 4 & 3 & 2 & 1 \\
\hline \multicolumn{5}{|l|}{ Compl. total } \\
\hline TTR & Ref & $1.3(1.1$ to 1.5$), p=0.033$ & $1.9(1.6$ to 2.3$), p<0.001$ & 2.4 (2.0 to 2.9 ), $p<0.001$ \\
\hline Variability & Ref & $1.1(0.9$ to 1.3$), \mathrm{p}=\mathrm{NS}$ & $1.4(1.2$ to 1.7$), p=0.001$ & 2.6 (2.1 to 3.1$), p<0.001$ \\
\hline \multicolumn{5}{|l|}{ Bleedings } \\
\hline TTR & Ref & $1.3(0.9$ to 1.8$), \mathrm{p}=\mathrm{NS}$ & $2.2(1.7$ to 3.0$), p<0.001$ & 2.9 (2.1 to 3.9$), p<0.001$ \\
\hline Variability & Ref & $1.2(0.9$ to 1.7$), p=N S$ & 1.8 (1.3 to 2.4$), p<0.001$ & 2.9 (2.1 to 3.9$), p<0.001$ \\
\hline \multicolumn{5}{|c|}{ Thromboembolic events } \\
\hline TTR & Ref & $1.0(0.8$ to 1.4$), p=N S$ & $1.4(1.1$ to 1.9$), p=0.015$ & $1.4(1.03$ to 2.0$), p=0.03$ \\
\hline Variability & Ref & $1.1(0.7$ to 1.4$), p=N S$ & $1.2(0.9$ to 1.7$), p=N S$ & $1.8(1.3$ to 2.5$), p<0.001$ \\
\hline \multicolumn{5}{|l|}{ Death } \\
\hline TTR & Ref & $1.4(1.0$ to 2.0$), p=N S$ & 2.2 (1.6 to 3.0$), p<0.001$ & 4.0 (2.9 to 5.4 ), $p<0.001$ \\
\hline Variability & Ref & $0.7(0.5$ to 1.1$), p=N S$ & $1.0(0.8$ to 1.5$), \mathrm{p}=\mathrm{NS}$ & $2.9(2.2$ to 4.0$), p<0.001$ \\
\hline
\end{tabular}


Table 5 Risk of complications (HR) with $95 \% \mathrm{Cl}$ depending on warfarin treatment quality measured as TTR and INR variability divided into high/low using TTR $70 \%$ or the mean INR variability of 0.40 as cut-off

\begin{tabular}{|c|c|c|}
\hline End points studied & $\Delta S D-I N R \leq 0.40$ INR & $\Delta S D-I N R>0.40$ INR \\
\hline \multicolumn{3}{|l|}{ TTR $\geq 70 \%$} \\
\hline Bleeding & 1 (ref) & $1.41(1.07 \text { to } 1.84)^{*}$ \\
\hline Thrombosis & 1 (ref) & $1.31(1.002 \text { to } 1.72)^{*}$ \\
\hline All-cause death & 1 (ref) & $1.68(1.25 \text { to } 2.25)^{*}$ \\
\hline \multicolumn{3}{|l|}{ TTR $<70 \%$} \\
\hline Bleeding & $1.50(1.01 \text { to } 2.38)^{*}$ & $2.50(1.99 \text { to } 3.15)^{*}$ \\
\hline Thrombosis & 0.84 (0.47 to 1.48$)$ & $1.55(1.21 \text { to } 1.99)^{*}$ \\
\hline All-cause death & $2.44(1.58 \text { to } 3.78)^{*}$ & $3.34(2.62 \text { to } 4.27)^{*}$ \\
\hline
\end{tabular}

Another way of measuring quality of treatment with warfarin is INR variability. In a recently published study from Vanerio ${ }^{10}$ patients with AF showed that INR variability can be advantageously used to assess anticoagulation quality. Calculation of both $\mathrm{CHA}_{2} \mathrm{DS}_{2}$ VASc and INR variability may facilitate mortality prediction in patients with AF receiving warfarin. In a study from Labaf et $a l^{11}$ the ability of INR variability and TTR as a predictor of the combined end point of thromboembolism, major bleeding and death in patients with MHV prostheses were comparable. Again, the present study confirms the impact of INR variability showing an increased rate of each end point including thromboembolism in patients with less stringent INR control. The association between warfarin treatment quality and complications when INR variability and TTR were divided into quartiles was however more pronounced for TTR.

Furthermore, we sought to combine TTR and INR variability, that is, patients with TTR $\geq 70 \%$ were divided into low or high risk depending on their level of INR variability. Patients who had higher variability at the same high level of TTR had significantly higher risk of all types of complications (bleedings, thromboembolic events and death). Inversely, low INR variability in itself was not enough. Low TTR among patients with low INR variability had higher risk of bleeding or death, but not thromboembolic events. As TTR is calculated for an INR between 2 and 3, a patient with a high INR target with consequently higher mean actual INR could have a low TTR despite low INR variability, resulting in an increased risk of bleeding. It is important thus to maintain a high TTR and to try to keep INR values as stable as possible to avoid complications.

One important question is whether a target INR should be defined for each prosthetic valve position. Most of the patients with an aortic MHV have a target INR of 2.5 (range 2.0-3.0), whereas those with a MHV in the mitral position more often have a target INR of $3.0(2.5-3.5)$. In reality though, patients with an intended target INR might actually have a mean INR in the lower or higher end of the treatment range. We divided patients with MHV prostheses regarding their actual mean INR $-2.2-2.7$ or $2.8-3.3$ to reflect patients with low or high treatment intensity independently of their intended INR target level. When we compared patients with those two actual INR intervals among patients with heart valve prosthesis in the same position we could not observe that higher actual INR was better regarding any complication independently of prosthesis location. It is of course possible that there was a selection bias to higher/lower actual INR depending on comorbidity and other factors that we have no information about. The only significant difference found was that higher actual INR among patients with aortic heart valve prosthesis was related to higher risk of death, which is difficult to explain.

With the same classification, no significant difference in favour of higher treatment intensity could be observed after multivariable adjustment. Moreover, patients with higher actual mean INR had significantly higher risk of all complications, and death independently of prosthesis position. Thus higher treatment intensity might do more harm than good. Larger, randomised studies are needed to identify optimal INR levels, but our study indicates that an INR between 2.0 and 3.0 may be sufficient even for patients with a MHV prosthesis in the mitral position.

Using the INR target range 2.0-3.0 for most heart valve prostheses regardless of type or location, we would probably decrease the risk of bleeding complications. Since this is a retrospective study, a follow-up with a prospective randomised trial would be preferred but is not likely. Novel Oral Anticoagulants (NOACs) are, since the RE-ALIGN study comparing dabigatran and warfarin with worse outcomes for dabigatran, not indicated in patients with MHV prosthesis. ${ }^{23}$ Therefore we will, for the foreseeable future, have to rely on warfarin, where the treatment quality is of utmost importance.
Figure 1 Warfarin treatment intensity as measured by actual mean international normalised ratio (INR) and risk of complications. HR $(95 \% \mathrm{Cl})$ is calculated with the lower mean INR group as reference. Adjusted HR is adjusted for mechanical heart valve prosthesis position, atrial fibrillation, heart failure, hypertension, diabetes, stroke and age. ${ }^{*} p<0.05,{ }^{* *} p<0.01$, $* * * p<0.001$.

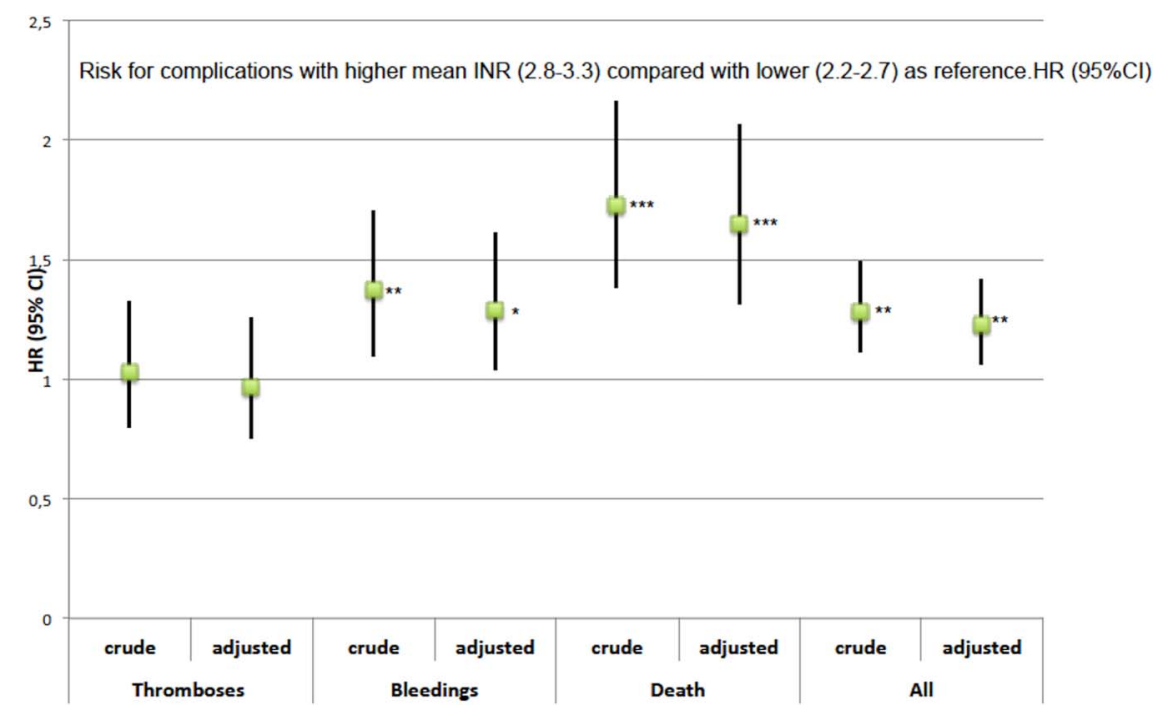

Grzymala-Lubanski B, et al. Heart 2017;103:198-203. doi:10.1136/heartjnl-2016-309585 


\section{Limitations}

Selection bias cannot be excluded in a retrospective registerbased, non-randomised study. However, the size of the study cohort and the fact that whole counties in Sweden include their patients in Auricula (both primary care and anticoagulation clinics), indicates that the results represent clinical practice in Sweden with limited selection bias. No data were available in the patient register on number of blood transfusions or reduction in haemoglobin levels; therefore the criteria for major bleeding we used may lead to an underestimation of the bleeding frequency. On the other hand, a haemoglobin reduction or blood transfusion, which does not result in a separate bleeding ICD-0 diagnosis, is probably less serious than those complications we included.

In conclusion, to reduce the risk for serious complications it is important to reach and maintain a high warfarin treatment quality. Both a high TTR and a low INR variability are of importance. No benefit of higher warfarin treatment intensity could be observed for any valve type or position.

Key messages

\section{What is already known on this subject?}

- Higher time in therapeutic range (TTR) reduces risk for serious complications among patients with mechanical heart valve prostheses. At the same time lower international normalised ratio (INR) variability also reduces risk for serious complications.

- Patients with mechanical heart valve prostheses have different treatment intensities depending on valve location and comorbidity.

\section{What might this study add?}

- TTR and INR variability show stronger association with rate of complications when combined together than each of them separately.

- Higher treatment intensity (mean INR 2.8-3.3) was associated with higher bleeding rate but not less thromboembolic events when compared with lower intensity (mean INR 2.2-2.7) regardless of valve prosthesis location and comorbidity.

\section{How might this impact on clinical practice?}

- A high emphasis should be placed on keeping TTR high and INR variability low. A lower treatment intensity corresponding to INR range 2.0-3.0 might be reasonable for most patients with mechanical heart valve prosthesis both in aortal and mitral position.

Contributors AS and PJS designed the study. BG-L and HR extracted and analysed data. BG-L drafted the manuscript. All authors critically reviewed the manuscript, contributed to its revision, and approved the final version submitted.

Funding The study was supported by the Department of Research and Development, County Council of Vasternorrland (LVNFOU415651) and The Heart Foundation of Northern Sweden.

\section{Competing interests None declared.}

Ethics approval The study was approved by the regional ethical review board in Umeå, Sweden (EPN nr 2011-349-31M, 2012-277-32M and 2016-30-32M).

Provenance and peer review Not commissioned; externally peer reviewed.

\section{REFERENCES}

1 Sun JC, Davidson MJ, Lamy A, et al. Antithrombotic management of patients with prosthetic heart valves: current evidence and future trends. Lancet 2009;374:565-76.

2 Swedeheart/Hjärtkirurgi. Årsrapport. 2014. http://www.ucr.uu.se/hjartkirurgi

3 Bonow RO, Carabello BA, Chatterjee K, et al. 2008 Focused update incorporated into the ACC/AHA 2006 guidelines for the management of patients with valvular heart disease: a report of the American College of Cardiology/American Heart Association Task Force on Practice Guidelines (Writing Committee to Revise the 1998 Guidelines for the Management of Patients With Valvular Heart Disease): endorsed by the Society of Cardiovascular Anesthesiologists, Society for Cardiovascular Angiography and Interventions, and Society of Thoracic Surgeons. Circulation 2008;118:e523-661.

4 Guyatt GH, Akl EA, Crowther M, et al. American College of Chest Physicians. Introduction to the ninth edition: Antithrombotic Therapy and Prevention of Thrombosis, 9th ed: American College of Chest Physicians Evidence-Based Clinical Practice Guidelines. Chest 2012;141(Suppl 2):48S-52S.

5 Vahanian A, Alfieri O, Andreotti F, et al., Joined Task Force on the Management of Valvular Heart Disease of the European Society of Cardiology (ESC); European Association for Cardio-Thoracic Surgery (EACTS). Guidelines on the management of valvular heart disease (version 2012). Eur Heart J 2012;33:2451-96.

6 Wan $Y$, Heneghan C, Perera R, et al. Anticoagulation control and prediction of adverse events in patients with atrial fibrillation: a systematic review. Circ Cardiovasc Qual Outcomes 2008;1:84-91.

7 Butchart EG, Payne N, Li HH, et al. Better anticoagulation control improves survival after valve replacement. J Thoracic Cardiovascular Surg 2002;123:715-23.

8 Grzymala-Lubanski B, Labaf A, Englund E, et al. Mechanical heart valve prosthesis and warfarin-treatment quality and prognosis. Thromb Res 2014;133:795-8.

9 Lind M, Fahlén M, Kosiborod M, et al. Variability of INR and its relationship with mortality, stroke, bleeding and hospitalisations in patients with atrial fibrillation. Thromb Res 2012;129:32-5.

10 Vanerio G. International normalized ratio variability: a measure of anticoagulation quality or a powerful mortality predictor. J Stroke Cerebrovasc Dis 2015;24:2223-8.

11 Labaf A, Själander A, Stagmo M, et al. INR variability and outcomes in patients with mechanical heart valve prosthesis. Thromb Res 2015;136:1211-15.

12 Yearly Report Auricula. 2013. http://www.ucr.uu.se/auricula

13 Jernberg T, Attebring MF, Hambraeus K, et al. The Swedish Web-system for Enhancement and Development of Evidence-based care in Heart disease Evaluated According to Recommended Therapies (SWEDEHEART). Heart 2010;96:1617-21.

14 Ludvigsson JF, Andersson E, Ekbom A, et al. External review and validation of the Swedish national inpatient register. BMC Public Health 2011;11:450.

15 Rosendaal FR, Cannegieter SC, van der Meer FJ, et al. A method to determine the optimal intensity of oral anticoagulant therapy. Thromb Haemost 1993;69:236-9.

16 Sandén P, Renlund H, Svensson PJ, et al. Warfarin treatment complications do not correlate to CTTR when above 70. Thromb Res 2015;136:1185-9.

17 Camm AJ, Lip GY, De Caterina R, et al., ESC Committee for Practice Guidelines (CPG). 2012 focused update of the ESC Guidelines for the management of atrial fibrillation: an update of the 2010 ESC Guidelines for the management of atrial fibrillation. Developed with the special contribution of the European Heart Rhythm Association. Eur Heart J 2012;33:2719-47.

18 Fihn SD, McDonell M, Martin D, et al. Risk factors for complications of chronic anticoagulation: a multicenter study. AnnInternMed 1993;118:511-20.

19 Fihn SD, Callahan CM, Martin DC, et al. The risk for and severity of bleeding complications in elderly patients treated with warfarin. The National Consortium of Anticoagulation Clinics. Ann Intern Med 1996;124:970-9.

20 Rosner B. Fundamentals of biostatistics. 7th edn. Cengage Learning Inc, 2010.

21 Grzymala-Lubanski B, Själander S, Renlund H, et al. Computer aided warfarin dosing in the Swedish national quality registry AuriculA-Algorithmic suggestions are performing better than manually changed doses. Thromb Res 2013;131:130-4.

22 Jowett $\mathrm{S}$, Bryan S, Poller L, et al. The cost-effectiveness of computer-assisted anticoagulant dosage: results from the European Action on Anticoagulation (EAA) multicentre study. J Thromb Haemost 2009;7:1482-90.

23 Eikelboom JW, Connolly SJ, Brueckmann M, et al. Dabigatran versus warfarin in patients with mechanical heart valves. N Engl J Med 2013;369:1206-14. 